\title{
Particle Induced X-Ray Emission Examination in Post-Mortem Brains
}

\author{
Jacques De Reuck \\ Department of Neurology, University Hospital, Gent (Belgium) \\ *Corresponding Author: Jacques De Reuck, Department of Neurology, University Hospital, Gent \\ (Belgium)
}

\begin{abstract}
Background: Particle induced X-ray emission (PIXE) allows to demonstrate the distribution of different minor and trace elements in post-mortem brains.

Objective: This article reviews the available data on PIXE in normal and diseased human post-mortem brains.

Methodology: Fresh non-formalin brain samples have to be used. The brain dissection has to be performed in a sterile room and in order to avoid the risk of metal contamination it is performed with molybdenum instruments. The brain samples are weighed, freeze-dried and weighed again to determine the wet-to-dry weight ratio. Afterwards the samples are submitted to acid digestion. Ten $\mu l$ of the obtained solution are piped onto a target film and submitted to proton beam irradiation. The PIXE spectrum shows the levels of potassium, calcium, manganese, iron, cupper, zinc, selenium and rubidium.

Results: The distribution of the minor and trace elements in normal brains vary according to the regions and in structures, involved in the same physiological function or morphologically similar. They predominate in the gray matter structures. In the rare diseased brains examined with PIXE the alteration of the minor and trace elements differ according to the underlying disease.

Discussion: It can be concluded that post-mortem PIXE analysis can be an additional tool to compare the pathology of normal to diseased brains.
\end{abstract}

Keywords: Particle induced X-ray emission, Post-mortem brains, Wet-to-dry weight ratio, Potassium, Calcium, Manganese, Cupper, Zinc, Selenium, Rubidium.

\section{INTRODUCTION}

Particle induced X-ray emission (PIXE) is an Xray spectrographic technique, which can be used for the non-destructive, simultaneous elemental analysis of solid, liquid or aerosol filter samples. Energetic protons initiate the X-ray spectrum by exciting the inner shell electrons in the target atoms [1]. PIXE allows a multi-analysis of biological material [2]. In the human brain it demonstrates a spectrum of eight elements. The dry weight concentrations of potassium (K), calcium $(\mathrm{Ca})$, manganese $(\mathrm{Mn})$, iron $(\mathrm{Fe})$, cupper $(\mathrm{Cu})$, zinc $(\mathrm{Zn})$, selenium $(\mathrm{Se})$ and rubidium $(\mathrm{Rb})$ can be determined with this technique [3]. The accuracy of the method has been previously shown by comparison of animal brain matter examined with PIXE analysis and with instrumental neutron activation analysis [4]. There are topographic differences in concentrations of these elements depending on the degree of neuronal density of the examined structure [5].
Brain metal homeostasis is altered in neurodegenerative and cerebrovascular diseases [6]. Using other methods such as magnetic resonance imaging and quantitative susceptibility mapping many studies have mainly focussed on the quantification of the $\mathrm{Fe}$ content in normal and diseased brains [7-9].

In rat brains the Fe concentration is the highest in the cytoplasm of neocortical oligodendrocytes, followed by microglia and astrocytes and less of all in neurons [10].

\section{Methodology}

Formalin fixation of the brain has to be avoided mainly because of the lost of extra-cellular and intra-cellular fluid of the tissues. It shows only a part of the complete biochemical "picture" of the tissue samples [11].

For the dissection of the non-formalin fixed brain special adequate surgical instruments and tools as well as an adequate sampling procedure are needed [12]. The brain dissection has to be 
performed in a sterile room and in order to avoid the risk of metal contamination it is performed with molybdenum instruments [13].

In our laboratory fresh brains are removed at autopsy, according to standard procedures, within 72 hours after death and sealed in a polyethylene bag. They are then placed in a deep-freezer at $-30^{\circ} \mathrm{C}$ for a period of 14 days. At about 12 hours before the dissection the frozen brains are removed from the freezer, and placed in a refrigerator at $-2^{\circ} \mathrm{C}$ until the actual dissection is performed. The tissue samples are taken from representative parts of the cerebral cortex, cerebral white matter, basal ganglia, thalamus, brainstem and cerebellar cortex. In our laboratory 50 samples of each brain are removed. They are weighed, freeze-dried and weighed again, allowing the determination of the wet-to-dry weight ratio. Afterwards the samples are submitted to acid digestion. Ten $\mu 1$ of the obtained solution are piped onto a target film and submitted to proton beam irradiation. All concentration data obtained are expressed on a dry weight base. The PIXE spectrum of the individual samples is obtained by proton beam irradiation, measured with a Silicon detector. This procedure does not produce alterations in the trace element levels of the individual brain structures [14].

\section{RESUlts}

\section{PIXE Spectrum in Normal Brains}

The wet-to-dry weight ratio is the highest in the cerebral and cerebellar cortex (6-7 times), followed by the basal ganglia and thalamus (5-6 times) and the lowest in the cerebral white matter (3-4 times).

The PIXE values of $\mathrm{K}, \mathrm{Ca}$ and the 6 trace elements are expressed in dry weight ratios [14].

The $\mathrm{K}$ content is between 15.000 and 20.000 $\mu \mathrm{g} / \mathrm{g}$ in the cerebral and cerebellar cortex, and in the basal ganglia and the thalamus. In the cerebral white matter it is between 5.000 and $10.000 \mu \mathrm{g} / \mathrm{g}$ dry.

The Ca content is between 500 and $700 \mu \mathrm{g} / \mathrm{g}$ in the cerebral and cerebellar cortex. In the basal ganglia, thalamus and cerebral white matter it is between 250 and $350 \mu \mathrm{g} / \mathrm{g}$.

The Mn content is between 2.2 and $3.2 \mu \mathrm{g} / \mathrm{g}$ in the basal ganglia and the thalamus and between 1.1 and $1.5 \mu \mathrm{g} / \mathrm{g}$ in the cerebral and cerebellar cortex, and in the cerebral white matter.

The $\mathrm{Fe}$ content is more than $500 \mu \mathrm{g} / \mathrm{g}$ in the basal ganglia and between 200 and $280 \mu \mathrm{g} / \mathrm{g}$ in the cerebral and cerebellar cortex, and in the thalamus. In the cerebral white matter the level is between $140-200 \mu \mathrm{g} / \mathrm{g}$.

The $\mathrm{Cu}$ content is more than $36 \mu \mathrm{g} / \mathrm{g}$ in the basal ganglia and cerebellar cortex. In the cerebral cortex and thalamus it is between 18 and 26 $\mu \mathrm{g} / \mathrm{g}$, while in the cerebral white matter it is as low as 9 up to $13 \mu \mathrm{g} / \mathrm{g}$.

The $\mathrm{Zn}$ content is between 60 and $84 \mu \mathrm{g} / \mathrm{g}$ in the cerebral cortex, basal ganglia, thalamus and cerebellar cortex. It is between 30 and $42 \mu \mathrm{g} / \mathrm{g}$ in the cerebral white matter.

The Se content is between 0.8 and $1.2 \mu \mathrm{g} / \mathrm{g}$ in the cerebral cortex, basal ganglia, thalamus and cerebellar cortex, while only between 0.4 and $0.6 \mu \mathrm{g} / \mathrm{g}$ in the cerebral white matter.

The $\mathrm{Rb}$ content is between 14 and $16 \mu \mathrm{g} / \mathrm{g}$ in the cerebral cortex, thalamus and cerebellar cortex. In the basal ganglia and the cerebral white matter it is between 10 and $12 \mu \mathrm{g} / \mathrm{g}$.

During normal aging the concentrations of $\mathrm{K}$ and $\mathrm{Rb}$ tend to decrease while there is an augmentation of $\mathrm{Ca}, \mathrm{Fe}, \mathrm{Zn}$ and $\mathrm{Se}$ [15].

According to some studies the major and trace element concentrations differ between the right and left hemispheres [16-17], depending of the individuals are right- or left handed [18].

\section{PIXE Spectrum in Brain Diseases}

Only a few neurodegenerative diseases have been examined with PIXE.

In Alzheimer's disease the senile plaques contain significantly more $\mathrm{Fe}, \mathrm{Cu}$ and in particular of $\mathrm{Zn}$, compared to normal brains $[19,20]$.

With PIXE analysis the increase of $\mathrm{Fe}$ in he substatia nigra is confirmed in Parkinson's disease [21].

In status epilepticus a $\mathrm{Ca}$ increase linked to a decrease of $\mathrm{K}$ is observed in the pars reticularis of the substantia nigra and the globus pallidus [22].

In acute non-haemorrhagic cerebral infarcts the wet-to-dry weight ratio and the $\mathrm{Ca}$ content are significantly increased mostly in the basal ganglia and cerebral white matter (Fig.1-2). The Fe level is mainly augmented in the cerebral cortex and white matter. On the other hand, there is a severe loss of $\mathrm{K}, \mathrm{Cu}$ and $\mathrm{Rb}$, while the levels of $\mathrm{Zn}$ and $\mathrm{Mn}$ remain unchanged (Fig. 34) [23]. In haemorrhagic cerebral infarcts all these changes are more pronounced compared to non-haemorrhagic ones [24]. In post-mortem brains of patients with an acute cerebral infarct, 
treated with anti-oedema medication, the wet-todry ratio is significantly decreased in the treated group, compared to the non-treated one. The $\mathrm{Ca}$ and $\mathrm{Fe}$ concentrations are lowered in the treated group while the $\mathrm{K}, \mathrm{Rb}$ and $\mathrm{Cu}$ levels are higher. No differences are observed for $\mathrm{Zn}$ and Se [25].

\section{PIXE Analysis of Middle Cerebral Artery Infarct}

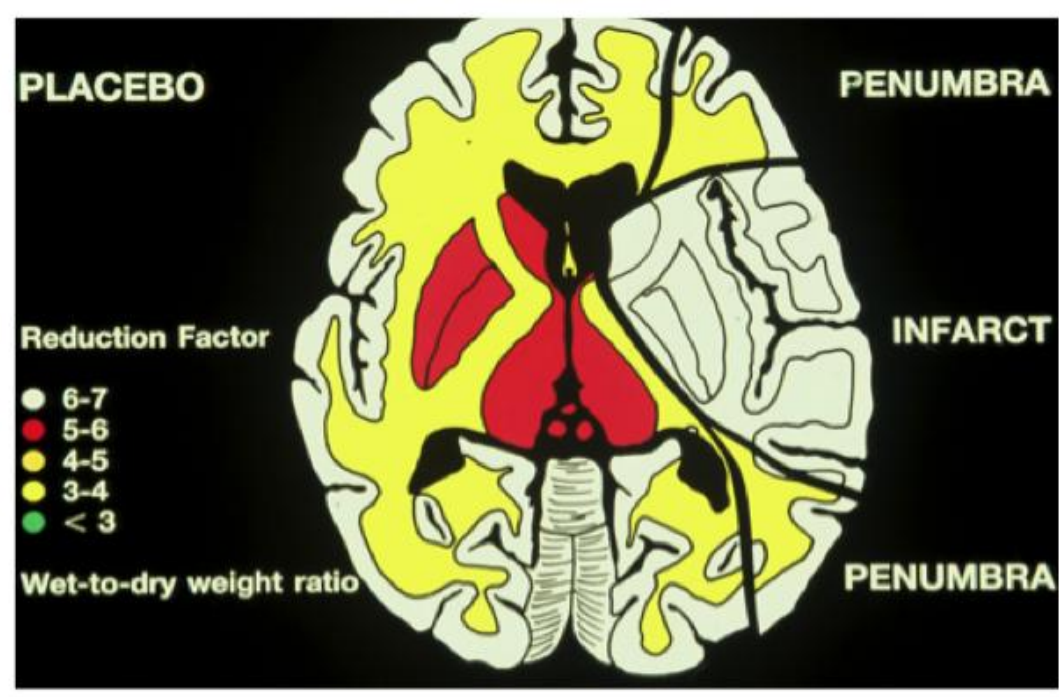

Figure1. In the normal brain (on the left) the wet-to-dry weight ratio is the highest in the cerebral and cerebellar cortex, followed by the basal ganglia and thalamus and low in the cerebral white matter. In the acute middle artery cerebral infarct (on the right) it is increased in the cerebral white matter and basal ganglia.

\section{PIXE Analysis of Middle Cerebral Artery Infarct}

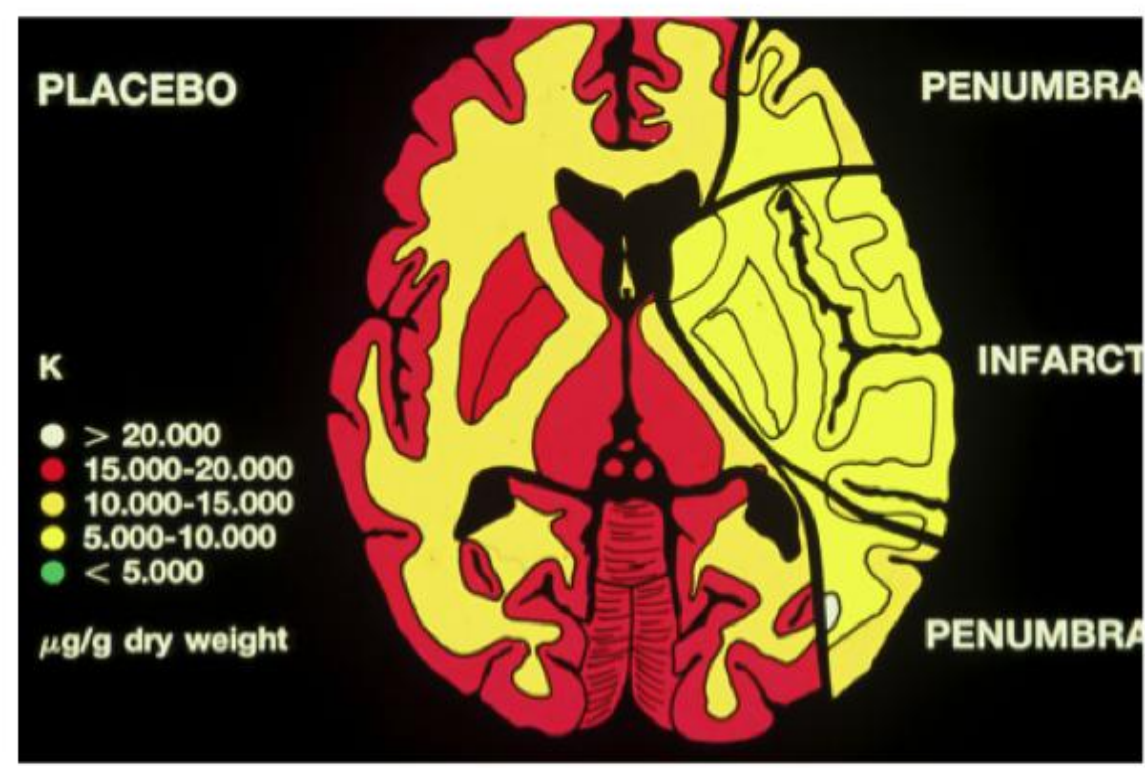

Figure2: In the normal brain (on the left) the K level is high in the cerebral and cerebellar cortex, basal ganglia and thalamus while low in the cerebral white matter. In the cerebral infarct and its penumbra (on the right) it is globally decreased. 


\section{PIXE Analysis of Middle Cerebral Artery Infarct}

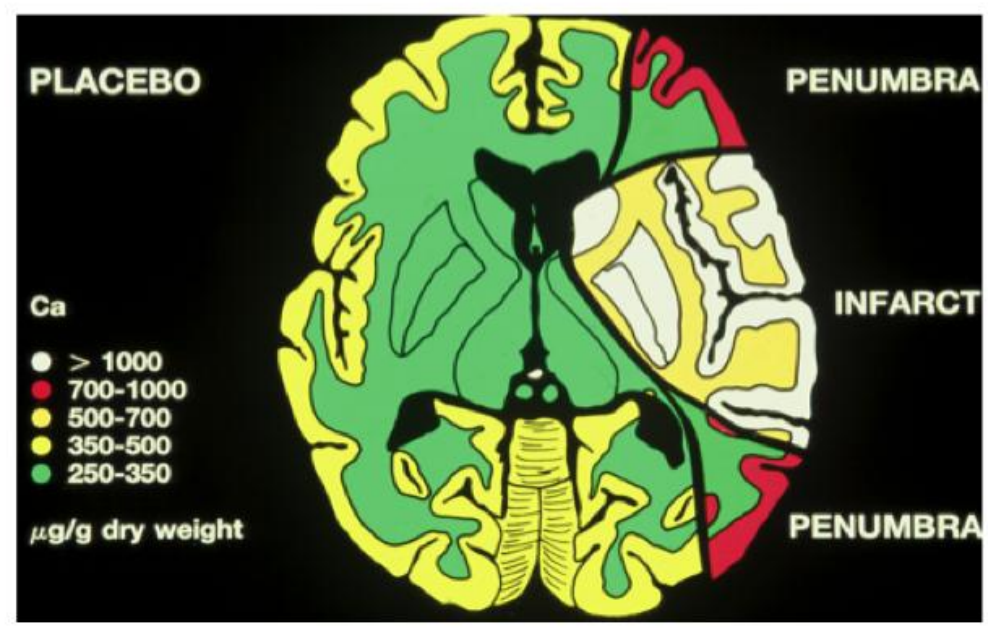

Figure3: In the normal brain (on the left) the Ca level is moderately high in the cerebral and cerebellar cortex, while low in the basal ganglia, thalamus and the cerebral white matter. In the cerebral infarct and its penumbra (on the right) it is globally increased in the cerebral infarct and in the cerebral cortex of the penumbra.

\section{PIXE Analysis of Middle Cerebral Artery Infarct}

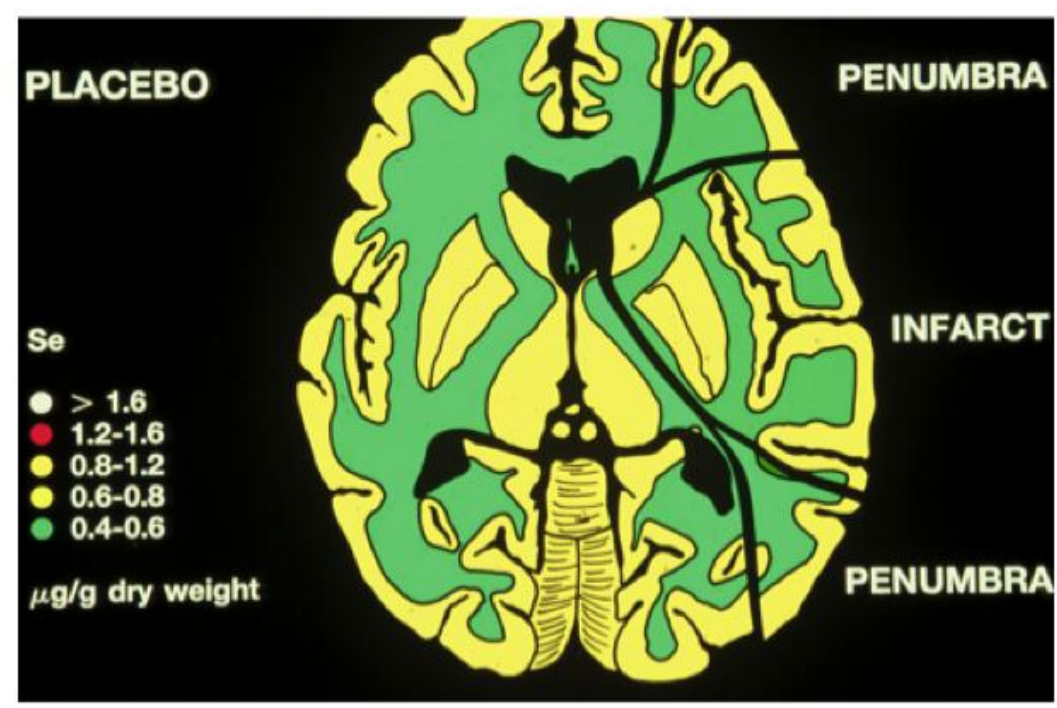

Figure4: In the normal brain (on the left) the Mn level is moderately high in the basal ganglia and thalamus, while low in the cerebral and cerebellar cortex, and the cerebral white matter. In the cerebral infarct (on the right) the Mn levels are unchanged compared to the normal control.

\section{DISCUSSION}

This study demonstrates the heterogeneous distribution of minor and trace elements in the different structures of the normal brain. There is a clustering of all gray matter structures and a clustering of all white matter components. Also, structures, involved in the same physiological function or morphologically similar regions often conglomerate in one substructure [14]. K, $\mathrm{Mn}$ and $\mathrm{Cu}$ levels can increase in specific regions of the brain during physiological processes such as memory consolidation [26].

In Alzheimer's disease it is known that increased levels of $\mathrm{Cu}, \mathrm{Fe}$ and particularly $\mathrm{Zn}$ can accelerate aggregation of amyloid beta peptide [19]. 
Previous studies have already demonstrated Fe accumulation in the substantia nigra of Parkinson brains, mainly in the severe forms of the disease [27]. In the early stages of the disease it is found to be restricted to the pars compacta of the substantia nigra [28]. In advanced stages $\mathrm{Fe}$ deposition extends to the pars reticularis of the sustantia nigra, the red nucleus and the globus pallidus [29].

The accumulation of $\mathrm{Ca}$ and the decrease of $\mathrm{K}$ in the deep brain structures in status epilepticus is a secondary phenomenon due to the intensity of the ischaemic damage [30].

Brain oedema, reflected by the increased wet-todry ratio, is due to disruption of the blood-brain barrier in acute ischaemic stroke, leading to accumulation of $\mathrm{Ca}$ and $\mathrm{Fe}$ in the infarcted tissue. Also a further increase of $\mathrm{Fe}$ is observed in older infarcts compared to recent ones, while the $\mathrm{Ca}$ level remains unchanged. This must be explained by a still ongoing leakage at the level of the blood-brain barrier. Also $\mathrm{Mn}, \mathrm{Zn}$ and $\mathrm{Se}$ levels are enhanced, whereas $\mathrm{K}$ and $\mathrm{Rb}$ levels show a tendency to return to normal [31].

It can be concluded that neuropathological PIXE analysis can be an interesting additional tool to examine post-mortem normal and diseased brains.

\section{REFERENCES}

[1] Johansson TB, Akselsson R, Johansson AE. Xray analysis: elemental trace analysis at the $10^{-12} \mathrm{~g}$ level. Nuclear Instruments Methodology. 1970; 84: 141-14

[2] Maenhaut W. Multi-element analysis of biological materials by particle-induced X-ray emission. Scanning Microscopy.1990; 4: 43-59.

[3] Duflou, H, Maenhaut, W, De Reuck, J. Application of principal component and cluster analysis to the study of the distribution of minor and trace elements in normal human brain. Chemometrics and Intelligent Laboratory Systems.1990; 9: 273-286.

[4] Duflou H, Maenhout W, De Reuck J. Application of PIXE analysis to the study of the regional distribution of trace elements in normal human brain. Biological Trace and Elemenl Research.1987; 13: 1-17.

[5] Duflou H, Maenhout W, De Reuck J. Regional distribution of potassium, calcium and trace elements in normal human brain. Neurochemistry Research.1989. 14:1099-1112.

[6] Carmona A, Roudeau S, Pernin L, Carcenac C, Vantelon D, Savasta M,Ortega R. Mapping chemical elements and iron oxidation states in the substantia nigra of 6-hydroxydopamine lesioned rats using correlative immuno histochemistry with proton and synchrotron micro-analysis. Frontiers of Neuroscience. 2019; 13: 1014. Doi: 103389/fnins.2019.01014.

[7] Bilgic B, Pfefferbaum A, Rohfing T, Sullivan EV, Adalsteinsson E. MRI estimates of brain iron concentration in normal aging using quantitative susceptibility mapping. Neuroimage. 2012; 59: 2625-2635.

[8] Yan F, He N, Lin H, Li R. Iron deposition quantification: Applications in the brain and liver. Journal of Magnetic Resonance Imaging. 2018; 48: 301-317.

[9] De Reuck J, Auger F, Durieux N, Maurage CA, Deramecourt V, Cordonnier C, et al. Comparison of iron deposition in subcortical structures of brains with Parkinsonian syndromes: A post-mortem 7.0-tesla magnetic resonance study. Internal Journal of Neurology Research.2019; 1:10-13.

[10] Reinert A, Morawski M, Seeger J, Arendt T, Reinert T. Iron concentrations in neurons and glial cells with estimates on ferritin concentrations. BMC Neuroscience. 2019; 20: 25. Doi: 10.1186/s12868-019-0507-7.

[11] Hackett MJ, McQuillan, JA, El-Assaad F, Aitken JB, Levina A, Cohen DD, et al. Chemical alterations of murine brain tissue induced by formalin fixation: implications for biospectroscopic imaging and mapping studies of disease pathogenesis. Analyst. 2011;136: 2941-2952.

[12] Zecca L, Pietra R, Goi C, Mecacci C, Radice D, Sabbioni E. Iron and other metals in neuromelanin, substantia nigra, and putamen of the human brain. Journal of Neurochemistry. 1994; 62: 1097-1101.

[13] Gelbart WZ, Johnson RR. Molybenum sintercladding of solid radioisotope targets. Instruments. 2019, 3; doi /103390/ 3010011.

[14] Maenhout W, Hebbrecht G, De Reuck J. Examination of regional distribution of minor and trace elements in normal human brains by PIXE and chemometric techniques. Nuclear Instrumental Methodology.1993; B75: 180-187.

[15] Hebbrecht G, Maenhaut W, De Reuck J. Brain trace elements and aging. Nuclear Instruments and Methods in Physical Research. 1999; 150: 208- 213.

[16] Stedman JD, Spyrou NM. Major and trace element concentration differences between right and left hemispheres of the "normal" human brain. Nutrition. 1995; 11 (5 Suppl): 542-545.

[17] Panasyl AE, Spyrou NM, Ubertalli LC, Akanie GA, Part P. Differences in trace element concentrations between the right and left hemispheres of human brain using INAA; J Radioanalytic Nuclear Chemistry. 2000; 244: 205-207.

[18] Wang D, Li Yh Wang H. Do left- and righthanded people have similar iron deposition in 
the basal ganglia? Journal of Computed Assistant Tomography. 2016; 40: 26-33.

[19] Lovell MA, Robertson JD, Teesdale WJ, Campbell JL, Markesbery WR. Copper, iron and zinc in Alzheimer's disease senile plaques. Journal of Neurological Science.1998;158: 47-52.

[20] Braidy N, Poljak A, Mario C, Rutlidge H, Rich A, Javasena T, et al. Metal and complementary molecular bioimaging in Alzheimer's disease. Front Aging Neuroscience. 2014; 6:138. Doi: 10.3389/fnagi.2014.000138.

[21] Watt F. Nuclear microscope analysis in Alzheimer's and Parkinson's disease: A review. Cellular and Molecular Biolology.1996;42: 17-26.

[22] Inamura K, Martins E, Themner K, Tapper S, Pallon J, Lovestam G, et al. Accumulation of calcium in the substantia nigra lesions induced by status epilepticus. A microprobe analysis. Brain Research. 1990; 514: 49-54.

[23] Duflou H, Maenhaut W, De Reuck J. Trace element alteration associated with cerebral infarction; in Meyer IS, Lechner H, Reivich M, Ott EO (eds): Cerebral Vascular Disease 7. Proc $14^{\text {th }}$ Salzburg Conf, Salzburg. Sept 29-Oct 1,1988. Amsterdam, Elsevier, 1989, pp 209-212.

[24] Hebbrecht G, Maenhaut W, De Reuck J. Comparison of trace element alterations and water content in haemorrhagic and nonhaemorrhagic cerebral infarcts. Cerebrovascular Disease. 1994; 4: 412-416.

[25] De Reuck J, Hebberecht G, Maenhaut W. Influence of Neurotropin on the water content and regional distribution of two minor and six trace elements in human brains affected by recent middle cerebral artery infarcts. Cerebrovascular Disease. 1993; 3: 94-98.
[26] Jobim PFC, Dos Santos CEI, Jeromel L, Pellicon P, Amaral L, Dias JF. Changes in the element concentration of the dorsal hippocampus CA region during memory consolidation and reconsolidation. Journal of Chemical Neuroanatomy. 2018; 90:49-56.

[27] Riederer P, Sofic E, Rausch WD, Schmidt B, Reynolds GP, Jellinger $\mathrm{K}$, et al. Transition metals, ferritin, gluthione and ascorbic acid in parkinsonian brains. Journal of Neurochemistry. 1998; 52:515-520.

[28] Jellinger K, Paulus W, Grundke-Iqbal I, Riederer P, Youdim MB, et al. Brain iron and ferritin in Parkinson's and Alzheimer's diseases. Journal of Neural TransmissionParkinson Disease and Dementia Section. 1990; 2:327-340.

[29] Guan X, Xuan M, Gu Q, Huang P, Liu C, Wang $\mathrm{N}$, et al. Regionally progressive accumulation of iron in Parkinson's disease as measured by quantitative susceptibility mapping. NMR in Biomedicine, 2017, 30. doi:10.1002/ nbm. 3489.

[30] Aggarwal M, Li X, Grohn O, Sierra A. Nucleispecific deposits of iron and calcium in the rat thalamus after status epilepticus revealed with quantitative susceptibility mapping (QSM). Journal of Magnetic Resonance Imaging. 2018; 47: 554-564.

[31] Duflou H, Maenhout W, De Reuck J. Trace elements in human brain: Regional distribution and alterations in structures affected by cerebral infarction. In: Bratter P, Schramel P, eds. Trace Element Analytical Chemistry in Medicine and Biology. Berlin, Walter de Gruyter.1988: 483490.

Citation: Jacques De Reuck, "Particle Induced X-Ray Emission Examination in Post-Mortem Brains", International Journal of Research Studies in Medical and Health Sciences. 2020; 5(6): 01-06.

Copyright: (C) 2020 Jacques De Reuck, This is an open-access article distributed under the terms of the Creative Commons Attribution License, which permits unrestricted use, distribution, and reproduction in any medium, provided the original author and source are credited. 